\title{
Further Development of Beauchamp and Childress’ Theory Based on Empirical Ethics
}

\author{
Mette Ebbesen $^{1 *}$, Svend Andersen ${ }^{2}$ and Birthe D. Pedersen ${ }^{3}$ \\ ${ }^{1}$ Centre for Bioethics and Nanoethics, Faculty of Arts, University of Aarhus, Denmark \\ ${ }^{2}$ Faculty of Arts, University of Aarhus, Denmark \\ ${ }^{3}$ Research Unit of Nursing, Faculty of Health Sciences, University of Southern Denmark, Denmark
}

\begin{abstract}
The American ethicists Tom L. Beauchamp and James F. Childress developed a framework of four ethical principles which are useful to analyze ethical complex cases in biomedicine. These four principles are respect for autonomy, beneficence, nonmaleficence, and justice. Beauchamp and Childress believe that their approach to manage ethical difficult cases is cross cultural i.e. that it can be used in different cultures such as American, European, and Asian cultures. However, some of their critics claim that the framework of the four principles is American in nature and for this reason it cannot be used in other cultures.
\end{abstract}

Beauchamp and Childress' theory is influential worldwide where it is taught to, and used by, students, nurses, physicians etc., therefore it is important to explore whether there are indications that this theory is actually useful in other cultures than the American and whether the theory should be modified for this purpose.

This article specifically examines how to investigate whether there are indications that the principles and method of Beauchamp and Childress are cross cultural. First, the theory of Beauchamp and Childress is introduced. Then a suitable method for studying the theory empirically is outlined. This empirical method was used for a Danish empirical study where Danish oncologists and Danish molecular biologists were interviewed. This study is reviewed in the article and it is pointed out that this study indicates that the four principles of Beauchamp and Childress are important for Danish biomedical practice. Lastly, it is concluded that similar empirical studies can be made in other cultural settings to investigate whether there are indications that the 'principles approach' of Beauchamp and Childress is cross cultural.

\section{Introduction}

Patients may be in difficult situations, and frequently it is hard to decide what ought to be done. For instance, a patient could suffer from serious cancer and be in deep crisis. In this situation it is difficult to choose among possible options of standard treatment, experimental treatment ${ }^{1}$, complementary treatment, and maybe withstanding treatment. It is hard for the patient and for the physician to find out what is in the best interest of the patient. The American ethicists Tom L. Beauchamp and James F. Childress have developed a framework of four ethical principles which may be a good starting point in such situations. These four principles are respect for autonomy (respecting the decisionmaking capacities of autonomous persons), nonmaleficence (avoiding the causation of harm), beneficence (providing benefits and balancing benefits, burdens, and risks), and justice (fairness in the distribution of benefits and risks) [1,2]. These principles form a moral framework which the patient and the physician can use to analyze the situation. The principles are prima facie binding meaning that they must be fulfilled in every situation if they do not conflict with other principles. If the principles conflict they ought to be specified and balanced [1].

According to Beauchamp and Childress, these four principles are not specific for biomedical ethics; they form the core part of a universal common morality. These ethicists think that morally serious persons do share some moral rules, principles, rights, and virtues in common. For instance, they know not to kill, to tell the truth, to nurture the young and dependent, and not to steal. These common norms are not implemented the same way in all cultures; however, the norms themselves are cross cultural. There is a transparent correlation between moral rules and principles of the common morality. For instance, the

${ }^{1}$ Experimental treatment does hear mean an unproven therapy which may or may not be superior to a current standard therapy. rule of do not kill is justified by the principle of nonmaleficence, the rule of tell the truth is justified by the principle of respect for autonomy, the rule of nurture the young and dependent is justified by the principle of beneficence, and the rule of do not steal is justified by the principle of justice. The common morality has normative force, i.e. it sets moral standards for everyone and all human conduct can be judged by its standards. This means that if persons violate the norms of the common morality they are unethical [1]. Beauchamp and Childress appeal to the common morality nonnormatively by claiming that we can study empirically whether the norms of the common morality are actually present in all cultures [1].

There is debate on whether Beauchamp and Childress' moral framework is cross cultural. Critics stress that it is limited to America and they have an idea of a specific European ethics in contrast to the American ethics of Beauchamp and Childress [3,4]. For instance, as an alternative to Beauchamp and Childress' account, the Danish ethicists Jacob Rendtorff and Peter Kemp believe that the moral concepts of autonomy, dignity, integrity, and vulnerability are useful for managing ethical difficult cases in Europe [4]. The Danish philosopher

*Corresponding author: Mette Ebbesen, Centre for Bioethics and Nanoethics Faculty of Arts, University of Aarhus, Taasingegade 3, Build. 1443, DK-8000, Aarhus C, Denmark, Tel: +45 8942 2312, E-mail: meb@teo.au.dk

Received November 14, 2011; Accepted January 19, 2012; Published January 25,2012

Citation: Ebbesen M, Andersen S, Pedersen BD (2012) Further Development of Beauchamp and Childress' Theory Based on Empirical Ethics. J Clinic Res Bioeth S6:e001. doi:10.4172/2155-9627.S6-e001

Copyright: @ 2012 Ebbesen M, et al. This is an open-access article distributed under the terms of the Creative Commons Attribution License, which permits unrestricted use, distribution, and reproduction in any medium, provided the original author and source are credited. 
and physician Soeren Holm states that the positive obligations of beneficence and justice are underdeveloped in Beauchamp and Childress' theory, these obligations need to be stronger for the theory to be functional in Europe [3]. The theory of Beauchamp and Childress has influence all over the world, where it is both taught to and used by students, nurses, physicians etc. Therefore it is important to investigate whether this theory is useful without modifications in other contexts than the American.

The aim of this article is specifically to examine how to investigate whether there are indications that the principles of Beauchamp and Childress are cross cultural; i.e. whether they can be used outside America, for instance in Europe and Asia. Therefore, this article is focused on the theory of Beauchamp and Childress and we will not go into general discussions of neither moral universalism versus particularism nor empirical ethics versus normative ethics.

In this article, first, the theory of Beauchamp and Childress is introduced. Second, a suitable method for studying the common morality of Beauchamp and Childress empirically is outlined. This method was used for a Danish empirical study of the theory of Beauchamp and Childress where Danish oncologists and Danish molecular biologists were interviewed. This study is reviewed in the article, and lastly, future perspectives for cross cultural empirical studies of the theory are outlined.

\section{Normative Justification of the Common Morality}

Beauchamp thinks that people in all cultures grow up with knowledge of some basic moral rules and an understanding of which demands that these rules make upon everyone. This body of basic moral rules constitutes morality in all cultures and Beauchamp calls this shared universal system of precepts the common morality or morality in the narrow sense. From this point of view, there is no difference in basic rules of morality in America, Denmark, Italy, China, and Japan. The common morality has normative force; hence it sets moral standards for everyone and if people do not live up to these standards they are immoral. Hence, all human behavior can rightly be judged by the demands of the common morality. According to Beauchamp, the rules of the common morality are a product of human conduct, experience, and history, meaning that they are learned in society $[1,5,6]$. He believes that human nature is similar enough that we will make similar judgments when we experience limited resources, need to cooperate ${ }^{2}$ etc. (personal communication with Beauchamp). The aims of the common morality are to promote human flourishing by thwarting circumstances causing the quality of people's lives to get worse [5]. Beauchamp writes that the "object of morality is to prevent or limit problems of indifference, conflict, hostility, scarce resources, limited information, and the like" [5]. He gives examples of moral principles and more specific rules that morally serious persons accept (Table 1).

A specific moral rule can be justified by more than one principle; so, there is a nonlinear correlation between specific rules and principles. Specifying a principle is to narrow the scope of the principle and making it action-guiding while retaining the moral obligations in the original form [2]. Hence, specifying a principle makes it useful for managing practical cases. For instance, the general principle of respect for autonomy can be specified into the more specific rule of respecting the privacy of others (Table 1).

Beauchamp accepts moral pluralism, he thinks that the moral rules of the common morality are not specified ${ }^{3}$ and interpreted ${ }^{4}$ the same way in all cultures because of different religious, cultural commitments, or the like. Hence, different moralities are present in the way Beauchamp calls morality in the broad sense $[1,6]$. According to Beauchamp, morality in the broad sense changes over time because of interpretation, specification, balancing, and negotiation. However, morality in the narrow sense is unchanging, it forms the constraining framework [6].

So, Beauchamp distinguishes between moral in the narrow sense which contains general norms that are abstract, universal, and contentthin and moral in the broad sense which contains specific norms that are concrete, non-universal, and content-rich [1]. This way Beauchamp combines universalism with multiculturalism.

\section{Managing Complex Cases of Biomedicine}

Beauchamp and Childress believe that four basic principles of respect for autonomy, beneficence, nonmaleficence, and justice form the core part of the common morality. These principles are basic for biomedical ethics and a good starting point for managing complex cases.

In Table 2 the four basic principles of the common morality are presented.

Beauchamp believes that it is "legitimate and rewarding" to analyze practical cases of biomedicine through the four general principles which are considered as prima facie binding [2]. A prima facie obligation is one that must be fulfilled in every circumstance unless it conflicts with a competing obligation. If there is conflict between two or more principles, first the obligations must be specified, next, the weight of each obligation must be determined and lastly, the obligations must be balanced [1].

According to Beauchamp, the first thing to do when managing practical cases of biomedicine is to specify the principles involved to create practical guidelines and procedures. He defines specification as "a process of reducing the indeterminateness of general norms to give them increased action guiding capacity, while retaining the moral commitments in the original norm" [2]. Specification is a narrowing of the scope and it adds content to the norms. It is performed in order to reduce the conflicts among the norms involved in the case [2]

\begin{tabular}{|ll}
\hline General principles & More specific rules \\
Nonmaleficence & Do not kill \\
Nonmaleficence & Do not cause pain or suffering to others \\
Beneficence & Prevent evil or harm from occurring \\
Beneficence & Rescue persons who are in danger \\
Beneficence & Nurture the young and dependent \\
Respect for autonomy & Respect the privacy of others \\
Respect for autonomy & Keep your promises \\
Justice & Do not steal \\
Justice & Do not punish the innocent \\
Justice & Protect and defend the rights of others \\
Justice & Give equal considerations under the law
\end{tabular}

Table 1: Examples of principles and more specific rules of the common morality (or morality in the narrow sense) $[5,6]$

${ }^{2}$ As a Hume scholar, Beauchamp may have an eye to Hume's understanding of human nature and morality in general.

${ }^{3}$ Specification here means narrowing the scope of a principle making it action guiding

${ }^{4}$ Interpretation means telling what a principle is about. 
Citation: Ebbesen M, Andersen S, Pedersen BD (2012) Further Development of Beauchamp and Childress' Theory Based on Empirical Ethics. J Clinic Res Bioeth S6:e001. doi:10.4172/2155-9627.S6-e001

Specification requires that the norms are extended "by both narrowing their scope and generalizing to relevantly similar circumstances" [1].

Norms involved in practical cases often need to be balanced. Balancing moral norms involves judgments about the relative weights and strengths of the norms. So, acts of balancing are supported by good reasons. Often, balancing cannot be generalized to other cases, since the reasons given to outweigh a norm often "are specific to the needs of this patient or this family in this circumstance" [1]. So, in contrast to specification, balancing is specific for the actual case at hand [1]. Beauchamp and Childress write that many different kinds of considerations are involved in the process of balancing. How physicians balance different norms often involves "sympathetic insight, humane responsiveness, and the practical wisdom of evaluating a particular patient's circumstance and needs" [1]. However, to reduce intuition and open-endedness, Beauchamp and Childress list some conditions that must be fulfilled to justify the infringement of one prima facie norm to adhere to another (Table 3 ).

In the article 'Methods and principles in biomedical ethics' published in Journal of Medical Ethics [2], Beauchamp analyses a case where an American Jehovah's Witness accepts the authority of that tradition and refuses a blood transfusion recommended by the physicians. The subsequent case analysis is freely adapted from Beauchamp's article. In the case at hand, the religious commitments of the patient conflict with the healing commitments of the physicians. The Jehovah's Witness has autonomously chosen to accept the doctrines of his faith [1,2]. In this case, the following two principles conflict: respect for autonomy of the patient and beneficence of the doctors (the case does not involve a principle of distributive justice, since a blood transfusion cannot be seen as highly expensive medical material in western societies). The following two rules do conflict:

1. It is morally objectionable to risk dead for a patient whose life threatening condition can be medically managed by nonexpensive medical material.

2. It is morally objectionable to disrespect a patient's refusal of treatment [2].

Beauchamp specifies rule 2 into rule 2.1. (Where much of the content of rule 2 is intact):

2.1. It is morally objectionable to disrespect a patient's refusal of treatment, unless the refusal is nonautonomous and presents a significant danger to the patient [2].

Since the Jehovah's Witness has autonomously chosen to follow the directions of this tradition, the specified rule 2.1. Clearly says that the refusal of the patient should be respected and compelling a blood transfusion cannot be justified under any conditions [2].

Imagine another case where American parents committed to Jehovah's Witness faith refuse a blood transfusion for their two years old child. Are the physicians morally obligated to respect this refusal or can compelling a blood transfusion being justified? The following two rules do conflict:

1. It is morally objectionable to risk dead for a patient whose life threatening condition can be medically managed by nonexpensive medical material.

2. It is morally objectionable to disrespect a parental refusal of treatment [2].

The principle of respect for autonomy

- "As a negative obligation: Autonomous actions should not be subjected to controlling constraints by others" [1]

- $\quad$ "As a positive obligation, this principle requires both respectful treatment in disclosing information and actions that foster autonomous decision making" [1]. Furthermore, this principle obligates to "disclose information, to probe for and ensure understanding and voluntariness, and to foster adequate decision making" [1].

The principle of beneficence

- One ought to prevent and remove evil or harm

- $\quad$ One ought to do and promote good [1]

The principle of nonmaleficence

"One ought not to inflict evil or harm", where harm is understood as "thwarting, defeating, or setting back some party's interests" [1]

The principle of justice

Beauchamp \& Childress do not think that a single principle can address all problems of distributive justice [1]. They defend a framework for allocation that incorporates both utilitarian and egalitarian standards. A fair health care system includes two strategies for health care allocation: 1) a utilitarian approach stressing maximal benefit to patients and society, and 2) an egalitarian strategy emphasising the equal worth of persons and fair opportunity [1].

Table 2: The four basic principles of the common morality. A brief formulation of the four ethical principles: the principles of respect for autonomy, beneficence, nonmaleficence, and justice $[1,7,8]$

1. "Good reasons can be offered to act on the overriding norm rather than on the infringed norm".

2. "The moral objective justifying the infringement has a realistic prospect of achievement".

3. "No morally preferable alternative actions are available".

4. "The lowest level of infringement, commensurate with achieving the primary goal of the action, has been selected".

5. "Any negative effects of the infringement have been minimized"

6. "All affected parties have been treated impartially" [1]

Table 3: Conditions constraining balancing. Conditions that must be met to justify infringement of one prima facie norm in order to adhere to another [1,7,8]. 


\section{Beauchamp specifies rule 2 into rule 2.1.:}

2.1. It is morally objectionable to disrespect a parental refusal of treatment, unless the refusal constitutes child abuse, child neglect, or violates a right of the child [2].

2.1. Needs further specification stating what is meant by child abuse, child neglect, and the rights of the child. Without going more into details on the examination and specification of these concepts here, shortly, Beauchamp's view is that it is not only morally permitted but morally required "to overrule this parental refusal of treatment, because the refusal does constitute a form of child abuse, child endangerment, child neglect, or inattention to the rights of the child" [2]. So, in this case the right choice of the physician is to overrule the refusal of the parents and compel a blood transfusion to the child [2].

However, we must be aware, according to Beauchamp, specified moral frameworks developed through case analysis are works in evolvement, they are changeable and they can vary from person to person and from culture to culture [2].

\section{Empirical Justification of the Common Morality}

Some scholars believe that Beauchamp and Childress' common morality theory is controversial. Here we will go into three main critiques of the universality of Beauchamp and Childress' theory. First, the Danish philosopher and physician Soeren Holm wrote the following article in 1995: 'Not just autonomy - the principles of American biomedical ethics' [3]. Here, he focuses on whether Beauchamp and Childress express a typical American view and whether this view is transferable to other cultures, for instance Europe. Second, the Danish philosophers Jacob Rendtorff and Peter Kemp published the work 'Basic ethical principles in European bioethics and biolaw' in two volumes in year 2000 [4]. Rendtorff and Kemp do not find the approach of Beauchamp \& Childress convincing, and they developed an alternative theory based on the following four basic ethical principles: autonomy, dignity, integrity, and vulnerability. Rendtorff and Kemp regard Beauchamp and Childress' approach as specifically American focusing on the individual, and they believe that their alternative fills out an empty space in the American theory by protecting "the fragile and finite, bodily incarnated human person" and thereby leads to a wider view of the human person [4]. Third, ethicist Ruiping Fan from East Asia wrote two articles in 1997 questioning the universality of Beauchamp and Childress' theory $[9,10]$. He believes that there is not a universal shared basic content of bioethical principles. For instance, there is no "shared 'abstract content' between the Western bioethical principle of autonomy and the East Asian bioethical principle of autonomy" in the way Beauchamp and Childress suggest [9]. Even though these critical texts are written some years ago, they are by Beauchamp himself considered as the main critique of the universality of his and Childress' theory (personal communication with Beauchamp and lecture by Beauchamp in Rotterdam, the Netherlands in 2008).

Soeren Holm states that Beauchamp and Childress' theory is developed from American common morality and therefore reflects certain characteristics of American society. He states that this can clearly be seen in the underdevelopment of the principles of beneficence and justice [3]. He refers that the principle of beneficence of Beauchamp and Childress is stating that you only have an obligation of beneficence if it can be carried out without presenting significant risks, costs, or burdens. Holm agrees that a principle of beneficence must be restricted in degree and scope. However, he thinks that a principle of beneficence is meaningless if it does not contain a notion of the prospect of sacrifice of personal interests. This is in line with his critique of the principle of justice. Holm states that Beauchamp and Childress seem to place "the quest for a just society within the realm of the supererogatory, and outside of the obligatory, because the chance of reaching a just society is small (or non-existent), and the effort required great" [3]. Holm thinks that they have removed the demanding components of the principles of beneficence and justice and ended up with "a totally watered-down conception without any substance or moral bite" [3]. He states that Beauchamp and Childress' model is explicitly American in nature and argues that much of the content is only useful in America and that it cannot be transferred in any straightforward manner to other cultural settings [3]. Hence, he does not believe in the universality of Beauchamp and Childress' theory. Holm concludes that to "accomplish a relatively un-problematic transfer would be to build on the premise that the form of the ethical system is constant, i.e., the four principles point to important parts of morality in all cultures, but that the exact content and strength of the individual principles may vary between cultures" [3]. Here it seems that Holm's conclusion is in line with Beauchamp and Childress's argument since they say that the four principles (understood as morality in the narrow sense) are cross cultural, the principles have nothing more to do with American culture than with Danish or Japanese cultures, however, specification, interpretation, and balancing of the principles (understood as morality in the broad sense) may vary from culture to culture.

The Danish philosophers Jacob Rendtorff and Peter Kemp also believe that the four principles of Beauchamp and Childress are unsuited to Europe. They propose a specific European ethics in contrast to the American ethics of Beauchamp and Childress. They think that the moral principles of autonomy, dignity, integrity, and vulnerability are useful for analyzing ethical issues in Europe. Rendtorff and Kemp believe that their theory is "based on the protection of the fragile and finite, bodily incarnated human person" [4]. By focusing on the integrity and dignity of the individual, they think that their model leads to a wider view of the human person than Beauchamp and Childress' theory, which focuses on the autonomous individual [4]. Beauchamp replies to Rendtorff and Kemps critique. First of all, he states that it is wrong to believe in specific principles for Europe and furthermore, he states that what Rendtorff and Kemp call principles are not principles at all. For instance, the moral concept of integrity is a virtue. And vulnerability is a property or condition of persons. Next, he thinks that dignity is one of the most obscure moral concepts of bioethics since nobody actually knows what dignity is (personal communication with Beauchamp). Beauchamp and Childress write: "human dignity - an unclear notion that moral theory has done little to clarify" [1]. Lastly, Beauchamp writes that empirical investigation could prove him or his critics wrong [5]. However, we do not believe that empirical research could prove whether a universal common morality exists or not. We think that Beauchamp should soften this formulation up writing that scientific research could indicate whether he or his critics are wrong.

Ethicists Ruiping Fan from East Asia argues that the principle of respect for autonomy as formulated by Beauchamp and Childress differs from the East Asian principle of autonomy. He writes that these two principles of autonomy do not have an abstract content in common, they are two different principles. Basically, the Western principle demands self-determination whereas the East Asian principle requires family-determination. According to Fan, these two principles of autonomy "differ from each other in the most general sense and basic moral requirement" and the Western principle cannot be used in East Asia [9]. 
So, there are debates on whether the principles and method of Beauchamp and Childress are cross cultural; i.e. whether they can be used outside America, for instance in Europe and Asia. As mentioned, Beauchamp believes that empirical investigation could either confirm or falsify the hypothesis of the universality of his and Childress' theory [1]. As noted previously, we do not think that qualitative empirical investigation could neither confirm nor falsify the hypothesis, we believe that qualitative research could indicate whether a universal common morality does exist or not.

Beauchamp and Childress sketch the design of an empirical study to investigate the question. The hypothesis says that all morally serious persons adhere to the common morality (the four clusters of principles), hence only morally serious persons should be included in the study [1]. The question is then to select morally serious persons. First, persons should be screened to test whether they are committed to the objectives of morality (which "are those of promoting human flourishing by counteracting conditions that cause the quality of people's lives to worsen" [5]). According to Beauchamp, this can be tested by investigating whether the respondents adhere to the principle of nonmaleficence, since he regards this principle as the most basic of the four principles and writes that "it is unimaginable that any morally committed person would reject this principle. Nonmaleficence is therefore a reasonable starting point for an investigation [1]. Persons not adhering to the principle of nonmaleficence are not committed to morality and should therefore be excluded from the study. Next, it should be tested "whether cultural or individual differences emerge over the (most general) norms believed to achieve best the objectives of morality" [5]. Hence, it should be tested whether cultural or individual differences appear over the general principles of respect for autonomy, beneficence, justice, and related rules [1]. Beauchamp writes: "Should it turn out that the individuals or cultures studied do not share the norms that I hypothesize to comprise the common morality, then there is no common morality of the sort I claim and my particular hypothesis has been falsified" [5]. According to Beauchamp, it would be difficult specifically to design such an empirical study [5].

\section{Suitable Method for Empirical Study of the Common Morality}

In this section we will give a more detailed description on how an empirical study investigating indications of the existence of the common morality of Beauchamp and Childress could be designed. This method was developed for a Danish empirical study investigating the ethics of molecular biologists and cancer physicians [7]. The method draws on Lindseth \& Norberg [12] and Pedersen [11]. These researchers developed a phenomenological-hermeneutical method based on interviews to reveal and understand experienced phenomena $[11,12]$. Lindseth\&Norberg used this method specifically to reveal the morals and the ethical thinking of physicians and nurses $[13,14]$. According to these authors, this method can be used to elucidate the essential and understandable meaning of good and bad as actually lived in human experience [12]. They consider the approach of this method as phenomenological because the aim was to reveal and describe the understandable meaning of lived experience. According to Lindseth \& Norberg [12] and Pedersen [11], narrative interviews are an appropriate method for revealing the understandable meaning of lived experience. These narratives are transcribed and need interpretation; therefore the approach is hermeneutical. The phenomenological-hermeneutical approach was used both for the overall design of the interview guide and for the data analysis [7].
Based on Lindseth \& Norberg (2004) and Pedersen (1999), the ethical reasoning and experience of molecular biologists and cancer physicians were revealed in the current study by conducting semistructured interviews. In a semi-structured interview, the questions are open-ended and thematic. In the study, the phenomenological approach was applied at the beginning of the interview, when the respondent was asked to narrate his/her experience of ethically difficult situations as freely as possible. The interviewer asked questions aimed at promoting additional narration, such as "who?" and"what happened next?". Later on in the interview, there was a shift from the phenomenological approach characterised by abstaining from making judgements to a hermeneutical approach, where the interviewer encourages the interviewee to reflect on his/her narrative by asking "why?" and "how?". Here the approach was hermeneutic, since the respondent was asked to reflect and interpret on his/her narrative. This shows that the basic approach of the overall design of the interview guide was phenomenological-hermeneutical [7].

The analysis of the interview texts drew on the hermeneutic method developed by the French philosopher PaulRicoeur because he believes that interpretation theory provides us with answers to the question of how "we make sense of written discourse" [14]. Ricoeur regards interpretation as a particular case of understanding: "It understands applied to the written expressions of life" [14]. So, the analysis of interview texts followed Ricoeur's process of interpretation and was divided into three steps: 1) naïve reading (naïve interpretation), 2) structural analysis, and 3) critical interpretation. First, a naïve understanding of the text was formulated from initial readings (naïve readings). The text was then divided into units of meaning that were condensed and abstracted to form units of significance, subthemes, and themes, which were compared with the naïve understanding for validation (structural analysis) (Table 4). To see whether the themes validated or invalidated the naïve understanding, they were related to the naïve understanding. If the structural analysis invalidated the naïve understanding, the whole text was read again and a new naïve understanding was formulated and checked by a new structural analysis. This process of comparing the naïve reading and the structural analysis was repeated until the structural analysis validated the naïve understanding $[7,10,11,14]$. Finally, the text was again read as a whole, the naïve understanding and the themes were reflected with the research questions and the background literature in mind, and a comprehensive understanding was formulated (critical interpretation).

\section{Discussion}

To show that it is possible to investigate ethical considerations and principles of respondents empirically by the method mentioned, we will shortly summarize some of the results of the Danish empirical study for which the method was developed. The aim of the Danish empirical study was to investigate the ethical considerations and principles of Danish oncology physicians and Danish molecular biologists. This study was based on 12 semi-structured interviews with three groups of respondents: a group of oncology physicians working in a clinic at a public hospital and two groups of molecular biologists conducting basic research, one group employed at a public university and the other in a private biopharmaceutical company.

In this study, respondents were asked specifically whether they adhere to the principle of nonmaleficence. This is in line with Beauchamps recommendations for an empirical study of the common morality [1]. According to the study, molecular biologists explicitly considered nonmaleficence in relation to the environment, the 


\begin{tabular}{|c|c|c|c|}
\hline Respondent group & $\begin{array}{l}\text { Units of meaning } \\
\text { (What is said) }\end{array}$ & $\begin{array}{l}\text { Units of significance } \\
\text { (What is speaked about) }\end{array}$ & Themes \\
\hline $\begin{array}{l}\text { Molecular biologist } \\
\text { employed at the } \\
\text { university (MBU, Q1) }\end{array}$ & $\begin{array}{l}\text { "... you must inform them of their options and then } \\
\text { respect their decision." }\end{array}$ & Inform patients and respect their decision & $\begin{array}{l}\text { Respect for autonomy / Informed } \\
\text { consent } \\
\text { - Information } \\
\text { - Respect decision }\end{array}$ \\
\hline $\begin{array}{l}\text { Molecular biologist } \\
\text { employed in a private } \\
\text { biopharmaceutical company } \\
(\mathrm{MBP}, \mathrm{Q} 2)^{6}\end{array}$ & $\begin{array}{l}\text { "... if you were a seriously ill or terminally ill patient, } \\
\text { I think I would accept just about any treatment, } \\
\text { because you would accept the risk involved." }\end{array}$ & $\begin{array}{l}\text { Very sick patients are constrained by the } \\
\text { circumstances to a certain choice }\end{array}$ & $\begin{array}{l}\text { Respect for autonomy / Informed } \\
\text { consent } \\
\text { - External constraints } \\
\text { - Vulnerability } \\
\text { - Fragility }\end{array}$ \\
\hline $\begin{array}{l}\text { Oncology physician working } \\
\text { in the clinic (OPC, Q3) }\end{array}$ & $\begin{array}{l}\text { "... try to determine what is wrong with the patient, } \\
\text { what are our options, what are the patient's } \\
\text { wishes, ideas, and then we have to reach some } \\
\text { kind of mutual understanding, frame of reference, } \\
\text { and take it from there ... and how can we deal with } \\
\text { this in respect of that." }\end{array}$ & $\begin{array}{l}\text { Medical prognosis evaluation } \\
\text { Risk-benefit analysis } \\
\text { Patient's wishes and ideas } \\
\text { Mutual understanding } \\
\text { Respect }\end{array}$ & $\begin{array}{l}\text { Medical prognosis evaluation } \\
\text { - Risk-benefit analysis } \\
\text { Respect for autonomy / Informed } \\
\text { consent } \\
\text { - Patient's wishes and ideas } \\
\text { - Mutual understanding } \\
\text { - Respect }\end{array}$ \\
\hline $\begin{array}{l}\text { Oncology physician working } \\
\text { in the clinic (OPC, Q4) }\end{array}$ & $\begin{array}{l}\text { "... patients are very different and you must adjust } \\
\text { to their level as best you can and try to find out } \\
\text { what kind of language to speak and to sense if } \\
\text { they have understood what you have told them, } \\
\text { and maybe repeat it..." }\end{array}$ & $\begin{array}{l}\text { Positive obligation to adjust to the level of } \\
\text { the patient } \\
\text { Information } \\
\text { Understanding }\end{array}$ & $\begin{array}{l}\text { Respect for autonomy / Informed } \\
\text { consent } \\
\text { - Disclosing information } \\
\text { - Probing for understanding }\end{array}$ \\
\hline
\end{tabular}

${ }_{5}^{5}(\mathrm{MBU}, \mathrm{Q1})$ : Molecular biologist employed at a public university, quotation 1.

${ }^{6}(\mathrm{MBP}, \mathrm{Q} 2)$ : Molecular biologist employed in a private biopharmaceutical company, quotation 2.

${ }^{7}(\mathrm{OPC}, \mathrm{Q3})$ : Oncology physician working in the clinic at a public hospital, quotation 3.

Table 4. Example of structural analysis - the movement from what is said to what is speaked about, first by describing units of meaning (what is said) and next by formulating units of significance (what is talked about) and themes. This specific example of structural analysis is taken from the Danish empirical study for which the method was developed [7]

researchers' own health, and animal models; and only implicitly in relation to patients or human subjects. In contrast, considerations of nonmaleficence by oncology physicians related to patients or human subjects. This study indicated that oncology physicians and molecular biologists employed in a private biopharmaceutical company had the specific principle of beneficence in mind in their daily work. Both groups seemed motivated to help sick patients. Physicians and molecular biologists both considered the principle of respect for autonomy as a negative obligation in the sense that informed consent of patients should be respected. Molecular biologists stressed that very sick patients might be constrained by the circumstances to make a certain choice. However, in contrast to molecular biologists, physicians experienced the principle of respect for autonomy as a positive obligation because the physician, in dialogue with the patient, offers a medical prognosis evaluation based upon the patients' wishes and ideas, mutual understanding, and respect. Finally, this study disclosed a utilitarian element in the concept of justice as experienced by molecular biologists from the private biopharmaceutical company and egalitarian and utilitarian characteristics in the overall conception of justice as conceived by oncology physicians. Molecular biologists employed at a public university were, in this study, concerned with just allocation of resources; however, they do not support a specific theory of justice. Hence, this study indicated that the ethical principles of respect for autonomy, beneficence, nonmaleficence, and justice as formulated by Beauchamp \& Childress were related to the ethical reflections of the Danish oncology physicians and the Danish molecular biologists. Hence, the study suggested that these principles are important for Danish biomedical practice [7,16-18].

But this empirical study was limited to an investigation of Danish biomedical practice and as has been pointed out, Beauchamp \& Childress claim that their bioethical principles are part of a common cross cultural morality [1]. However, as mentioned previously, some of their critics state that the principle-based theory has been developed from the American common morality and that it reflects specific aspects of American society. Therefore it might not be transferable to other contexts and other societies [3]. Nonetheless, the results of the Danish study indicate that the principles of respect for autonomy, beneficence, nonmaleficence, and justice as formulated by Beauchamp \& Childress are transferable to Danish biomedical practice. Future perspectives of this empirical study are to investigate whether there are indications for a difference in the ethical considerations and principles at stake between physician oncologists working in different cultural settings, such as European, East Asian, and American cultures. Such a study would explore indications on whether Beauchamp \& Childress principles are cross cultural and thereby have a universal perspective. The future study could be based on 12 semi-structured interviews with three groups of respondents, for instance four physician oncologists working in clinics at public hospitals in Denmark, China, and USA. This future study may indicate whether a common morality of the kind proposed by Beauchamp and Childress does exist or not.

\section{Conclusion}

In this article we have examined how to investigate whether there are indications that the bioethical principles of Beauchamp and Childress are specifically western or whether they are cross cultural. Critics indicate that the principles are unsuited for Europe and East Asia. However, Beauchamp maintains that empirical research can be used to test the hypothesis that a common cross cultural morality based on the four principles does exist or not. We argued that indications for a common morality can be explored by qualitative research based on narrative interviews. We outlined a phenomenological-hermeneutical method which we have already used to investigate the ethics of Danish oncologists and molecular biologists. In this article we argued that this method is also useful to investigate the ethics of oncologists in European, East Asian, and American cultures. 
Citation: Ebbesen M, Andersen S, Pedersen BD (2012) Further Development of Beauchamp and Childress' Theory Based on Empirical Ethics. J Clinic Res Bioeth S6:e001. doi:10.4172/2155-9627.S6-e001

\section{References}

1. Beauchamp TL, Childress JF (2009) Principles of Biomedical Ethics, Oxford University Press.

2. Beauchamp TL (2003) Methods and principles in biomedical ethics. J Med Ethics 29: 269-274.

3. Holm S (1995) Not just autonomy--the principles of American biomedical ethics. $J$ Med Ethics 21: 332-338.

4. Rendtorff J, Kemp P (2000) Basic ethical principles in European bioethics and biolaw: autonomy, dignity, integrity and vulnerability. Denmark: Centre for ethics and law.

5. Beauchamp TL (2003) A defense of the common morality. Kennedy Inst Ethics J 13: $259-274$

6. Beauchamp TL (1997) Comparative Studies: Japan and America. In Japanese and Western Bioethics Ed. Kazumasa Hoshino, Kluwer Academic Publishers, The Netherlands.

7. Ebbesen M (2009) Bioethics in Theory and Practice. PhD Thesis, Faculty of Health Sciences, University of Aarhus, Denmark.

8. Ebbesen M (2011) Cross cultural principles for bioethics. Advanced Biomedical Engineering. (Editors) Gaetano D. Gargiulo, Alistair McEwan InTech publisher, Croatia.

9. Fan R (1997) Self-determination vs. family-determination: two incommensurable principles of autonomy: a report from East Asia. Bioethics 11: 309-322.
10. Fan $R$ (1997) Three levels of problems in cross-cultural explorations of bioethics: A methodological approach. In.: Kazumasa Hoshino (Editor) Japanese and Western Bioethics, Kluwer Academic Publishers, The Netherlands.

11. Pedersen BD (2005) Nursing practice, language and cognition. Ph.D-Thesis University of Aarhus, Denmark.

12. Lindseth A, Norberg A (2004) A phenomenological-hermeneutical method for researching lived experience. Scand J Caring Sci 18: 145-153.

13. Udén G, Norberg A, Lindseth A, Marhaug V (1992) Ethical reasoning in nurses and oncology physicians' stories about care episodes. J Adv Nurs 17: 10281034.

14. Lindseth A, Marhaug V, Norberg A, Udén G (1994) Registered nurses' and oncology physicians' reflections on their narratives about ethically difficult care episodes. J Adv Nurs 20: 245-250.

15. Ricoeur P (1976) Interpretation theory: discourse and the surplus of meaning Texas: The Texas Christian University Press.

16. Ebbesen M, Pedersen BD (2007) Empirical investigation of the ethica reasoning of physicians and molecular biologists - the importance of the four principles of biomedical ethics. Philos Ethics Humanit Med 2:23.

17. Ebbesen M, Pedersen BD (2008) The principle of respect for autonomy concordant with the experience of physicians and molecular biologists in their daily work? BMC Med Ethics 9: 5 .

18. Ebbesen M, Pedersen BD (2008) The role of ethics in the daily work of oncology physicians and molecular biologists - results of an empirical study. Bus Prof Ethics J 27: 75-101.
This article was originally published in a special issue, Bioethical Research: Theories and Practices handled by Editor(s). Mette Ebbesen, Ph.D., University of Aarhus, Denmark 